meeting in an east-Midland town, when the question of dental service for expectant and nursing mothers was raised, a member declared that the husbands required treatment rather than the wives. The belief in the power of the caul to confer protection and good luck is gradually dying out, but at one time cauls were carried by the shore fishermen all along the coast of eastern England to protect them from death by drowning. In addition to the criminal use of savin and pennyroyal for abortifacient purposes, the legitimate employment of herbal remedies, especially raspberry tea, is widely spread in the eastern counties and north-east London for relieving the many inconveniences and minor troubles of pregnancy.

\section{Uitra-Violet Lighting}

Mr. R. H. Fucer of the Lighting Section of the British Thomson-Houston Co. Ltd., has written a paper published in the Electrical Review for August 25 on the use in generating stations in war-time of ultra-violet lighting. The whole station could be bathed in ultra-violet energy and light produced only where needed, as, for example, on the handles of switches, meter scales, push buttons, telephones, doors, keyholes, tables, stairs, fire-extinguishers, etc., by the application to them of a dab of fluorescent paint or dye. Small press buttons should be surrounded by circles. Fuse positions can be delineated by outlining them, or by spotting the carriers with paint on the floor. In front of every switchboard a line should be painted about 12 inches away. The shapo of every obstruction near an open switchboard or in a control room should be delineated by floor lines or patches of paint. Fluorescent chalks are also available for writing emergency warnings. The waves given off by the black lamps used are of a definite wave-length and produce no sun-burning or other dangerous effects. They are used in connexion with invisible fluorescent laundry marking systems and have been in constant operation for several years without a single case of ill effects to operators. Ultra-violet lighting is recommended for the emergency lighting in generating stations and similar premises in the Home Office A.R.P. Department pamphlet entitled 'War Time Lighting Restrictions for Industrial and Commercial Premises'.

\section{African Linguistics}

THE International Institute of African Isanguages and Cultures publishes in the July number of Africa a survey of linguistic questions relating to Africa, which includes a number of tasks with which the Institute is concerned. The issue by the Institute of a "Short Guide to the Recording of African Languages" has produced results of no little importance in their bearing on the study and classification of African languages. Prof. D. Westerman has compiled a list of no less than thirty-one previously and littleknown languages which have been recorded through its uso. This material has been sent to the Institute. Some will be published; the remainder, with such additional linguistic material as may accrue from time to time, will be available at the Institute for consultation by students. A valuable indication of the linguistic work already done, and of the field still to be covered in this department of investigation in Negro Africa, will bo afforded by a series of articles which is to appear in Africa. The first in the current issue is a survey by Dr. Johannes Lukas of linguistic research between the Nile and Lake Chad. In addition to pointing out the regions to which future research can most usefully be directed, the series will serve as a preliminary classification of African languages. An interesting problem is discussed by Prof. C. M. Doke, who deals with the position and relation of European and Bantu languages in South Africa. While he admits that owing to political and economic factors European languages, and especially English, are ousting Bantu, he main. tains that certain of the Bantu languages will persist for their cultural value in literary development and their private, family, and devotional use. Other contributions to this issue of Africa deal with indigenous literature, the study of intonation and of phonetics, and the facilities for the study of African languages in Great Britain, on the Continent and in South Africa. Consideration of the relation between language study and anthropology is reserved for future consideration.

\section{Why Smallpox?}

IN an editorial so entitled in Public Health Reports of June 23, it is stated that the United States leads all the other nations in the world except India in the number of smallpox cases reported in 1937, when there were 11,673 cases in that country. In 1938 the disease was more prevalent than it has been during the past five years, the number of cases being approximately 15,000 . In 1936, according to the Health Section of the League of Nations, England and Wales, with a population of $40,839,000$, reported only 12 cases. France, with $41,906,000$ inhabitants, reported 273 cases, and Germany with a population of $67,346,000$ had no cases. Some of the States in the Union have had no smallpox for several years. New Jersey, for example, with a population of about $4,400,000$, has not had a case for more than seven years, while tho States of North Dakota, South Dakota, Montana, Idaho, Oregon, Wyoming and Utah, with a combined population less than that of New Jersey, reported a total of more than 12,000 cases during the same period. The persistence of smallpox in the United States is simply due to neglect of vaccination, the explanation though not excuse for this being the comparative mildness of the disease in recent years and the reduced incidence compared with fifteen or twenty years ago. The possibility of the malignant type developing from the mild type is a disputed question, but there is always the possibility of the malignant type being introduced from foreign countries, especially in these days of air travel.

\section{Olfactory Electricity}

IT is stated in the Beama Journal of July that electricity is now being used to measure a smell. Various electrical devices are used in everyday work to make measurements in the dornain of sight, touch 